\title{
EM BUSCA DOS SABORES RURAIS POMERANOS: PATRIMÔNIO, TURISMO E CONSUMO AO SUL DO BRASIL
}

\author{
In the Pursuit of Pomeranian Rural Flavors: \\ Heritage, Tourism and Consumption in Southern Brazil \\ Evander Eloi KRONE y Renata MENASCHE ${ }^{1}$ \\ Universidad Federal de Pernambuco / Universidad Federal de Pelotas (Brasil)
}

\section{Resumen}

Apesar de terem estado entre os primeiros imigrantes europeus que chegaram, há pouco mais de 150 anos, à Serra dos Tapes (Rio Grande do Sul, Brasil), devido a sua origem étnica e condição camponesa os pomeranos foram, por muito tempo, estigmatizados. Contudo, processo de sentido contrário tem sido observado nos últimos anos, com a criação de políticas locais de valorização do patrimônio cultural pomerano. O estudo evidencia que várias dessas iniciativas são pautadas na tentativa de resgate de formas tradicionais do «ser pomerano», processo em que o modo de vida do grupo - e em particular seus saberes e práticas alimentarestem sido convertido em atrativo turístico, oferecido ao consumo.

Palavras chave: patrimônio cultural pomerano, turismo rural, alimentação, imigração, campesinato, Rio Grande do Sul, Brasil

\section{Abstract}

Despite being among the first European immigrants who arrived, a little over 150 years ago, at Serra dos Tapes (Rio Grande do Sul, Brazil), because of their ethnic

1 Evander Eloi Krone es doctor en Antropologia, Programa de Pós-Graduação em Antropologia da Universidade Federal de Pernambuco (PPGA/UFPE). Correo electrónico: evanderkrone@gmail.com; Renata Menasche es doctora en Antropología, Programa de Pós-Graduação em Antropologia da Universidade Federal de Pelotas (PPGAnt/UFPel) y Programa de Pós-Graduação em Desenvolvimento Rural da Universidade Federal do Rio Grande do Sul (PGDR/UFRGS). Correo electrónico: renata.menasche@pq.cnpq.br. Fecha de recepción del artículo: 23 de septiembre de 2017. Fecha de aceptación: 15 de noviembre de 2017. 
origin and peasant condition, Pomeranians have been stigmatized for a long time. However, a reverse process has been observed in the last few years, with the establishment of local policies to safeguard and enhance the Pomeranian cultural heritage. The survey shows that many of these initiatives are grounded in the attempt to rescue traditional ways of «being Pomeranian», a process in which the group's way of life - and particularly their cookery knowledge and practiceshas been converted into a tourism attraction focused on consumption.

Key words: cultural heritage, Pomerians, rural tourism, eating, immigration, peasantry, Rio Grande do Sul, Brazil

\section{INTRODUÇão}

Neste artigo nos propomos a refletir sobre processos relacionados a políticas públicas de patrimonialização da cultura pomerana desenvolvidas no extremo Sul do Brasil, particularmente no município de São Lourenço do Sul, estado do Rio Grande do Sul. Dessa forma, busca-se discutir algumas das ações de valorização do patrimônio cultural pomerano em espaços em que a comida é associada a uma modalidade de turismo cultural. O objetivo do trabalho é evidenciar como práticas e saberes da alimentação são, em contexto de exploração turística, apropriados e recriados pelo mercado, evidenciando contradições do processo.

Como mostram Giancarla Salamoni e Carmen Waskievicz (2013), no período que antecedeu a colonização europeia, a região em estudo fora ocupada pelos índios Tapes, pertencentes à família linguística Tupi Guarani. Ainda de acordo com essas autoras, a partir do século XVIII, nas terras de planície da região, luso-brasileiros e portugueses estabeleceram grandes fazendas pastoris. Esse sistema de produção consolidou a indústria de produção de charque (carne bovina salgada, cortada e seca ao sol), com emprego intensivo de mão de obra de escravos negros. A partir de 1848, o Governo brasileiro passou a promover a imigração e a formação de colônias agrícolas, cedendo terras na Serra dos Tapes, área montanhosa não ocupada pelas fazendas pastoris. É nesse contexto que imigrantes alemães, franceses, italianos, poloneses e pomeranos se estabeleceram no extremo sul do Brasil.

A presente conjuntura histórica, cultural e social desta região remonta, assim, ao século XIX, quando o Governo Imperial do Brasil incentivou a criação de projetos privados de colonização, cedendo terras cultiváveis a 


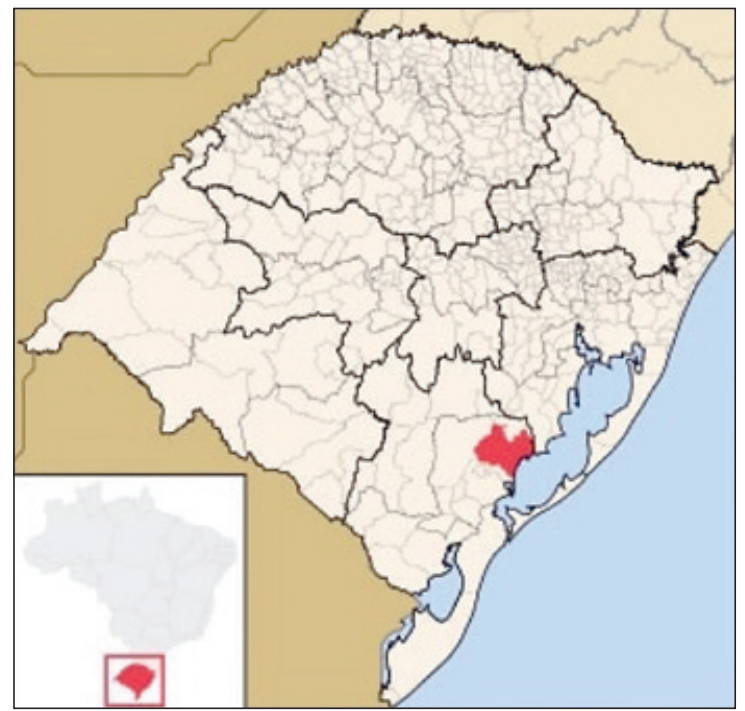

Figura 1: Localização do município de São Lourenço do Sul. Fonte: Wikipédia, 2017.

empresários que promovessem a vinda de imigrantes europeus. ${ }^{2}$ Foi nesse contexto que o empresário de origem prussiana, Jacob Rheingantz, fundou, em 1858, a colônia ${ }^{3}$ São Lourenço (Iepsen: 2008) -que posteriormente daria origem ao município de São Lourenço do Sul (Figura 1) —, trazendo à região imigrantes do Reino da Prússia, ${ }^{4}$ vindos das províncias da Prússia Renânia ${ }^{5}$ e Pomerânia. ${ }^{6}$

2 Segundo Giralda Seyferth (1997), o Estado brasileiro, embasado em teorias racialistas e evolucionistas, promoveu a imigração europeia com o objetivo de «branquear» a população brasileira. A imigração europeia assumiu, assim, para o Estado, função civilizadora da sociedade brasileira, haja vista que os imigrantes europeus eram considerados mais aptos e intelectualmente superiores, especialmente em comparação à população indígena e negra, que compunham a maior parte da população brasileira.

3 Segundo Jean Roche (1969), as palavras colono e colônia têm origem no idioma alemão, respectivamente nos termos Kolonist (que se refere ao homem que desbrava a terra) e Kolonie (que diz respeito a um lote ou estabelecimento rural).

4 O Reino da Prússia, compreendendo principalmente os territórios que atualmente pertencem à Alemanha e à Polônia, perdurou de 1701 a 1918, porém constituindo-se, a partir de 1871, como Estado-membro do Império Alemão.

5 Região situada a oeste da atual Alemanha.

$6 \mathrm{Na}$ atualidade, o território da antiga província da Pomerânia encontra-se repartido, sob o domínio da Polônia e da Alemanha. 
Quando esses imigrantes chegaram à região estudada, o Estado Alemão atual ainda não existia, porém, com a dissolução do Reino da Prússia e a unificação e criação do Império Alemão, no final do século XIX, a expressão «alemão» seria empregada para identificar especialmente os imigrantes de origem renana (Thum: 2009). É preciso salientar que, ainda que não haja números precisos sobre essa imigração, os pomeranos eram o grupo numericamente majoritário, estimados em $80 \%$ do total (Vilela: 2008). ${ }^{7}$

Os imigrantes renanos - a partir de agora identificados como alemãese pomeranos vivenciaram um processo compartilhado de ocupação da nova colônia. No entanto, enquanto os pomeranos desenvolveram sua vida no campo, os imigrantes alemães se destacaram na vida urbana e comercial, ocupando posições de poder nas arenas política e econômica, local e regional. Ainda, a partir de instâncias formadoras, como igrejas e escolas, em boa medida os alemães impuseram aos pomeranos valores germânicos (Thum: 2009). Desta forma, ainda que constituíssem o grupo étnico majoritário, os pomeranos experimentaram um processo de subordinação e estigmatização, associado a sua origem étnica e condição camponesa, contexto em que muitos preferiam esconder sua origem, vindo a assumir a identidade alemã (Thum: 2009).

Estudando processos que, nesta região, levaram à invisibilidade da cultura pomerana, Carmo Thum (2009) indica entre os elementos que contribuíram para a desvalorização da identidade e cultura pomeranas a referência à condição camponesa dos imigrantes pomeranos. Segundo esse autor, parcela significativa dos imigrantes alemães estabelecidos em São Lourenço do Sul migraram para atividades urbanas, mais valorizadas socialmente, enquanto que os pomeranos permaneceram, no meio rural, sendo a eles associado o estigma da condição camponesa, relacionada a pobreza e atraso. Julgados à luz de valores citadinos, os pomeranos seriam percebidos como sujeitos inferiores, uma vez que saberes, fazeres, práticas culturais e modos de vida camponeses têm sido historicamente associados a atraso econômico, social e intelectual. ${ }^{8}$

7 Segundo Bosenbecker (2011), os registros e documentos oficiais comumente identificaram genericamente os imigrantes como prussianos.

8 Ao analisar as relações entre campo e cidade a partir da literatura inglesa, Raymond Williams (1990) enfatiza que, com a Revolução Industrial, as grandes cidades converteramse em símbolo de modernidade, a ideia de progresso industrial sendo associada como característica da cidade e da própria civilização, enquanto o modo de vida rural foi sistematicamente depreciado. 
Outra razão para a desvalorização da cultura pomerana pode ser encontrada na forma como o próprio Estado os classificou diante de outros grupos étnicos. Em trabalho que analisa a influência da ideia de raça nas políticas de imigração do Brasil do século XIX, Giralda Seyferth (2002) mostra que imigrantes alemães e italianos eram classificados como mais perseverantes, resignados e habilidosos do que imigrantes de outras nacionalidades. Desta forma, imigrantes alemães e italianos eram considerados «bons trabalhadores» e, em relação a imigrantes de outras origens, como poloneses e pomeranos — vistos como etnicamente inferiores-, apareciam no topo de uma hierarquia étnica.

É assim que, ainda que presentes na região desde meados do século XIX, durante muito tempo os pomeranos estiveram à margem da sociedade local, permanecendo como grupo étnico invisibilizado em relação aos imigrantes de origem alemã. Tal estigmatização se deu em vários âmbitos da vida social do grupo, expressando-se na depreciação de suas características culturais, modos de falar, práticas alimentares e costumes. Talvez o maior indicador desse fenômeno seja a desvalorização da língua pomerana. Os imigrantes alemães que se estabeleceram em São Lourenço do Sul falavam o Hochdeutsch, ${ }^{9}$ enquanto a língua falada pelos pomeranos tinha sua origem nos dialetos e línguas do Plattdeutsch. ${ }^{10}$ A té por volta da Segunda Guerra Mundial, ${ }^{11}$ a língua predominante nas escolas e igrejas de São Lourenço do Sul era o Hochdeutsch. Ainda que no cotidiano familiar as crianças fossem socializadas na língua pomerana, nas instituições escolares eram alfabetizadas em Hochdeutsch. O mesmo ocorria em relação às instituições religiosas, em que a catequização, bem como os cultos religiosos, eram ministrados em Hochdeutsch. ${ }^{12}$ Desse

9 Segundo Ismael Tressmann (2008), o Hochdeutsch é originário das regiões altas e montanhosas da Alemanha e da Suíça.

10 A língua pomerana, também conhecida, por alguns nativos, como Plattdeutsch, é ágrafa. Segundo Marina Mujica (2013: 13), o pomerano tem influência eslava, germânica e itálica, sendo que «as línguas e dialetos tratados como baixo alemão [Plattdentsch] (das planícies ao norte) têm influência marcante do que mais tarde se denominou de línguas saxônicas». Já o Hochdeutsch tem influência de línguas celtas (Mujica: 2013).

11 Em meados dos anos 1940, o Estado brasileiro promoveu uma campanha de nacionalização, com objetivo de diminuir a influência dos imigrantes no país - especialmente aqueles com origem em países alinhados com a Alemanha durante a Segunda Guerra Mundial - e promover sua integração nacional. Entre as medidas tomadas pelo Estado estava a proibição do uso de línguas estrangeiras em espaços públicos, especialmente em escolas e igrejas.

12 Para maiores informações sobre a formação educacional e religiosa das comunidades pomeranas da região estudada, recomendamos ver o trabalho de Patrícia Weiduschadt (2007). 
modo, tanto as instituições escolares como as religiosas contribuíram para o aprofundamento de processos discriminatórios em relação à língua e cultura pomeranas. Segundo Thum (2009), os pomeranos foram colocados em posição subordinada diante dos alemães falantes do Hochdeutsch, sendo vistos como pertencentes a uma cultura menos desenvolvida. Assim, o Hochdeutsch assumiu o «valor simbólico de língua culta, sendo seu falante considerado mais esclarecido» (Thum, 2009: 131).

No entanto, a partir de meados dos anos 2000, observam-se na região mudanças no contexto antes descrito. Políticas de valorização do patrimônio cultural pomerano passaram a ser engendradas pelo poder público local —a partir da administração pública do município de São Lourenço do Sul- e é assim que, atualmente, esse grupo se encontra no centro de uma política que, valorizando a memória e patrimônio cultural das famílias rurais de origem pomerana, promove a reinvenção de seu passado.

Acreditamos que a recente reinvenção das práticas culturais pomeranas está associada a um processo mais amplo e vinculado à emergência de políticas de salvaguarda de bens de natureza imaterial, que ganharam corpo no âmbito nacional e internacional nas últimas décadas. Regina Abreu (2008) recorda que, desde a década de 1990, a Organização das Nações Unidas para a Educação, a Ciência e a Cultura - UNESCO, preocupada com o aprofundamento da globalização, recomendou aos estados nacionais que criassem políticas de proteção do patrimônio cultural imaterial, de modo a salvaguardar o conhecimento e as práticas culturais de diversos povos e comunidades. Alfredo Wagner (2010) chama atenção para o fato de que, no contexto brasileiro, nas últimas décadas, diversos grupos sociais passaram a acionar o patrimônio cultural como uma ferramenta para demandar reconhecimento e conquistas sociais.

Cabe ressaltar que, muito provavelmente, as iniciativas de valorização da cultura pomerana em São Lourenço do Sul tenham sido influenciadas por ações anteriores, que já vinham se desenvolvendo no Espírito Santo, estado que possui a maior colônia de imigração pomerana do Brasil. ${ }^{13}$

13 Além do Rio Grande do Sul, imigrantes pomeranos estabeleceram-se, no Brasil, também nos estados de Espírito Santo, Rondônia e Santa Catarina. Apesar de não haver números precisos, alguns pesquisadores (Tressmann: 2008) estimam que existam no Brasil ao menos 300 mil descendentes de pomeranos, dos quais aproximadamente a metade vive no Espírito Santo. 
Naquele Estado, vários municípios desenvolveram políticas de valorização da cultura pomerana, como a criação de lei reconhecendo o bilinguismo, tornando o pomerano língua oficial, ao lado do português.

Tais iniciativas parecem ter servido de inspiração para, na região estudada, a ocorrência de uma mudança de postura em relação a práticas culturais pomeranas, influenciando na criação de algumas das ações desenvolvidas no município de São Lourenço do Sul, entre as quais destacamos a rota turística Caminho Pomerano e a celebração Südoktoberfest. ${ }^{14}$

O poder público municipal de São Lourenço do Sul deu suporte à criação de uma rota turística rural baseada nas práticas culinárias, história e costumes pomeranos. É assim que, em 2008, surge o Caminho Pomerano, fundado por 37 sócios interessados em explorar atividades turísticas e econômicas associados às práticas culturais pomeranas. Ao longo do tempo, o roteiro sofreu alterações, algumas propriedades deixaram de ser ponto de visitação, enquanto outros pontos foram incluídos. Nem todos os membros do empreendimento recebem turistas em suas propriedades, sendo que alguns associados elaboram produtos e artesanatos, colocados à venda nos locais de visitação. $\mathrm{Na}$ época de realização desta pesquisa, o Caminho Pomerano contava com seis pontos de visitação e, segundo seus organizadores, em seus primeiros cinco anos de funcionamento foram recebidos cerca de três mil visitantes.

Agrega-se a esse processo de valorização da cultura pomerana a promoção de festas étnicas, como a Südoktoberfest, em que o visitante é convidado a saborear elaborações culinárias apresentadas como tradicionais da cultura pomerana, a exemplo do peito de ganso defumado, Rievelsback, ${ }^{15}$ Maischnaps, ${ }^{16}$ entre outras. A festa tem origem no final da década de 1980, quando jovens integrantes de um grupo local de danças folclóricas alemãs decidiram criar uma festa local, com o objetivo de promover o folclore, a

14 A tradução literal do termo é «festa de outubro do sul» e faz referência a celebração que ocorre anualmente no mês de outubro no sul do Estado do Rio Grande do Sul.

15 Uma espécie de bolinho frito elaborado à base de batatas, farinha de trigo e ovos. As batatas são raladas, de modo a constituir uma massa bem fina, à qual são acrescidos os ovos e a farinha de trigo para, na sequência, serem feitos os bolinhos, que serão fritos.

16 O Maischnaps é uma espécie de aguardente curtida com 32 ervas e produzida sempre durante o mês de maio. Para mais informações, ver o estudo de Mauricio Schneider \& Renata Menasche (2011). 
música e a culinária dos imigrantes de origem germânica (Krone: 2014). ${ }^{17}$ À época de sua criação, a Südoktoberfest era uma festa que celebrava essencialmente a cultura alemã, pois ainda não estava colocado o processo de valorização da cultura pomerana. Contudo, na medida em que políticas públicas locais passaram a contemplar o patrimônio cultural pomerano, a própria Südoktoberfest passou também a incorporar elementos da antes desvalorizada etnia pomerana.

Neste sentido, o Caminho Pomerano e a Südoktoberfest são tomados neste trabalho como espaços privilegiados de estudo, a partir dos quais procuramos apreender o processo de reinvenção da identidade e cultura pomeranas, promovido pelo poder público municipal. Pretendemos, neste quadro, evidenciar como as práticas alimentares do grupo foram recuperadas, manipuladas e exotizadas de modo a atender a demandas do mercado turístico, sem necessariamente encontrar paralelo em práticas sociais e vida contemporânea dos atores sociais.

A pesquisa, realizada entre 2011 e 2013, seguiu a tradição do método etnográfico, com observação participante, realização de entrevistas semiestruturadas junto a famílias rurais e informantes chave, além de um período de imersão a campo junto a comunidades e famílias rurais pomeranas. $^{18}$

A pesquisa a campo foi desenvolvida em três etapas distintas. Inicialmente, foram realizadas incursões em espaços de sociabilidade e celebração da comunidade de São Lourenço do Sul. Desta forma, foram etnografadas duas edições da Südoktoberfest, realizadas em 2011 e 2012, em que tivemos oportunidade de conhecer os gestores da festa e

17 Não há registros de estudos anteriores a respeito da celebração. Desta forma, a pesquisa de Evander Krone (2014), que dá base a este artigo, pode ser considerada pioneira.

18 Este trabalho foi desenvolvido a partir de dois projetos de pesquisa mais amplos - Cultura, patrimônio e segurança alimentar entre famílias rurais: etnografias de casos significativos (CNPq 559565/2010-0) e Saberes e Sabores da Colônia: modos de vida e patrimônio alimentar entre pomeranos no Brasil meridional (FAPERGS 1018354)—, compondo a agenda de pesquisa Saberes e Sabores da Colônia, conduzida no âmbito do Grupo de Estudos e Pesquisas em Alimentação e Cultura (GEPAC), sob coordenação da professora Renata Menasche. $\mathrm{O}$ estudo resultou na dissertação de mestrado intitulada Comida, memória e patrimônio cultural: a construção da pomeraneidade no extremo sul do Brasil (Krone: 2014), apresentada no Programa de Pós-Graduação em Antropologia da Universidade Federal de Pelotas. Esse e outros trabalhos produzidos no contexto dos projetos de pesquisa antes mencionados estão disponíveis no site do GEPAC (https:// www.ufrgs.br/gepac/). 
acompanhar o processo de organização da celebração. Paralelo a isso, percorremos também o roteiro Caminho Pomerano, conhecendo seus organizadores e locais de visitação. Neste período inicial, foram mapeados os principais interlocutores e porta-vozes das políticas locais de valorização da cultura pomerana.

Em um segundo momento, o procedimento metodológico consistiu na realização de entrevistas semiestruturadas, em profundidade, junto a informantes chaves, particularmente os atores sociais diretamente envolvidos nas políticas locais de patrimonialização. Foram então realizadas cinco entrevistas, três delas junto a participantes da Associação Caminho Pomerano, cujas propriedades rurais são pontos de visitação da rota turística rural. Outras duas entrevistas foram realizadas junto a dirigentes responsáveis pela organização da Südoktoberfest.

$\mathrm{Na}$ terceira fase da pesquisa, o trabalho de campo se deu através da imersão e integração entre famílias rurais do interior do município de São Lourenço do Sul. Por meio das redes de parentesco e vizinhança, buscouse ter acesso à vida social das comunidades rurais pomeranas, procurando, desta forma, apreender como as políticas locais de valorização da cultura pomerana reverberam nas práticas cotidianas e no imaginário social das famílias e comunidades rurais pomeranas. Além de conversas informais e registro de atividades vivenciadas no cotidiano, foram realizadas seis entrevistas em profundidade junto a famílias rurais pomeranas que se dedicam à produção de alimentos para autoconsumo aliada a atividades agrícolas voltadas ao comércio, particularmente a produção de leite e o cultivo de soja e/ou fumo.

$\mathrm{Na}$ primeira seção que segue esta introdução, analisamos o caso da Südoktoberfest, evidenciando como os gestores da festa acionam a alimentação de forma ideológica e como práticas alimentares pomeranas têm sido acionadas e recuperadas de modo a se tornarem atrativas ao turismo. Já na segunda seção, tomamos como universo empírico de análise o Caminho Pomerano, buscando mostrar como sabores da tradição pomerana são apresentados e consumidos no roteiro, em ambiente que sugere a originalidade das práticas sociais e o resgate do passado pomerano. $\mathrm{Na}$ última seção, que antecede as considerações finais deste trabalho, analisamos o contexto de famílias rurais pomeranas, destacando que a vida nas comunidades rurais pomeranas se desenvolve de modo bem distinto daquele apresentado e encenado aos turistas. 


\section{SÜDOKTOBERFEST: COMIDA, FESTA E TRADIÇÃO}

Jesús Contreras (2005) identifica a ocorrência, nos últimos anos, de uma «explosão» de patrimônios, resultante de um sentimento de nostalgia, presente em uma sociedade marcada pela homogeneidade. Desse modo, a busca contemporânea por recuperar patrimônios culturais pode ser entendida como uma espécie de reação à globalização e crescente homogeneização de modos de vida. O autor mostra que o sentimento de nostalgia reflete também na revalorização de pratos tradicionais, recuperação de receitas em processo de desaparecimento ou desaparecidas, bem como no reconhecimento de saberes e práticas associados à alimentação enquanto patrimônio cultural.

É sabido que, após a Segunda Guerra Mundial, houve um processo massivo de industrialização e homogeneização da alimentação. No último século, progressos obtidos nos âmbitos de produção, conservação, acondicionamento e transporte de alimentos conduziram a um movimento de intensificação de sua internacionalização e mercantilização. Alimentos como carnes, queijos, peixes, conservas, enlatados e bebidas atravessam fronteiras continentais e são distribuídos por grandes empresas agroalimentares. Como diz Jean Pierre Poulain (2004: 29), nunca na história da humanidade os alimentos estiveram tão deslocados «de seu enraizamento geográfico e das dificuldades climáticas que lhe eram tradicionalmente associadas». É nesse processo de globalização da alimentação, marcado - em contexto em que se dá o distanciamento dos consumidores da produção de alimentos e a multiplicação de produtos alimentícios disponibilizados- pela presença do desconhecido na comida, que se constitui o que tem sido caracterizado como ansiedade contemporânea diante da alimentação (Fischler: 1995).

Como também mostram Marcelo Álvarez e Luiza Pinotti (2000), a insegurança relacionada à alimentação industrializada gera movimento oposto, de revalorização de produtos locais, resgate de variedades vegetais e animais e de receitas tradicionais. É assim que, também em relação aos saberes e práticas da alimentação, produz-se uma «retórica da perda» (Gonçalves: 1996) ${ }^{19}$ e é nesse contexto que discursos preservacionistas

19 Segundo José Reginaldo Gonçalves (1996), os discursos sobre a preservação do patrimônio têm lastro em uma «retórica da perda», dado que a noção contemporânea de patrimônio foi implementada com base em políticas que lastimavam a perda de tradições e produções das elites. 
ganham forma e no qual são geradas as condições necessárias para que comida seja convertida em patrimônio cultural (Menasche: 2013).

Nesse quadro, em que a alimentação emerge como importante marcador identitário, no caso em estudo - e especialmente nas festas típicas-, ela se constitui como elemento de diferenciação étnica e afirmação de patrimônio cultural comum. É assim que a Südoktoberfest, tradicional festa germânica do município de São Lourenço do Sul, torna-se cenário deste estudo.

$\mathrm{Na}$ Südoktoberfest, a alimentação é acionada na delimitação de fronteiras étnicas, sendo constitutiva de discursos reificados a respeito da identidade e cultura pomeranas. Os gestores da Südoktoberfest expressam preocupação com a originalidade e autenticidade da festa, de modo que palavras como «típico» e «tradicional» estão entre as mais acionadas em seus discursos. Boa parte da alimentação oferecida na festa é pensada sob essa perspectiva, daí também a preocupação em obter ingredientes considerados genuínos como, por exemplo, o chope, necessariamente artesanal, ou as galinhas, que devem ter origem em produção local e não industrializada.

As festividades, que atraem expressivo fluxo regional de turistas e têm duração de três dias, contemplam a realização de um jantar típico, em que há apresentação de grupos de dança germânica. Também anima a festa a realização de bailes e jogos germânicos. Um dos pontos altos da celebração é o desfile de rua, que conta com significativa participação da população, que sai às ruas para assistir ao desfile dos grupos de dança e admirar os trajes característicos ${ }^{20}$ e as mascotes Walter e Wilma (Figura 2), um casal de bonecos-ganso que constitui a marca da festa. Carros, caminhões, tratores e bicicletas são enfeitados, comumente com as cores da bandeira alemã. Durante o trajeto, são distribuídos gratuitamente, para população e turistas, chope, linguiças, cucas, ${ }^{21}$ doces e outros alimentos considerados característicos da culinária alemã-pomerana.

20 Os homens geralmente vestem camisa de colarinho em tons claros, calças longas ou até a altura do joelho, suspensórios, coletes, meias até a altura do joelho e sapatos ou botinas fechados; já as mulheres costumam vestir chapéu ou tiara florida, avental ou blusa com mangas bufantes, acompanhada de colete, ou vestidos típicos, confeccionados em rendas ou bordados, podendo ser longos ou até a altura do joelho; nos pés, as mulheres geralmente calçam sapatilhas.

21 A cuca é preparada à base de farinha, ovos e manteiga, levando cobertura de açúcar e, em algumas de suas variações, sendo recheada com frutas. 


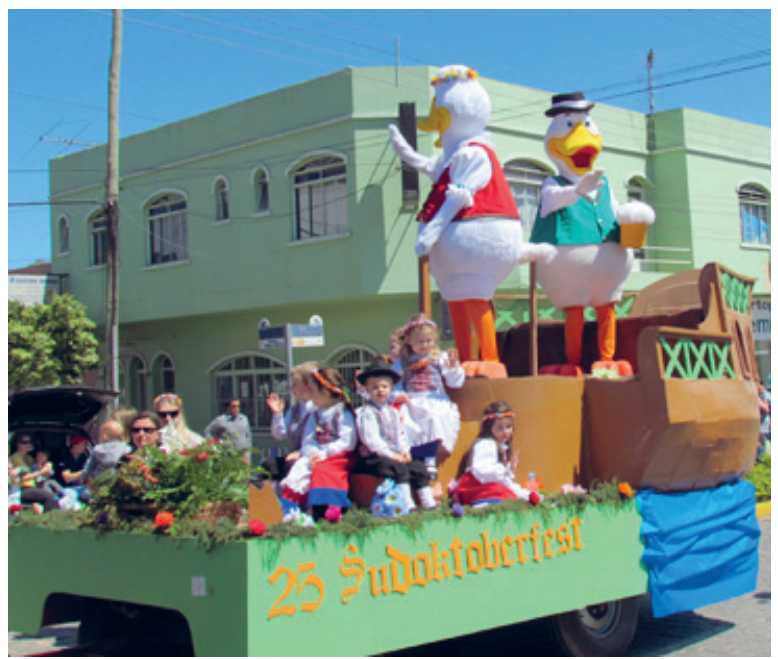

Figura 2: As mascotes Walter e Wilma durante o desfile de rua da $25^{\text {a }}$ Südoktoberfest em 2012. Fonte: Krone, 2014.

Outro destaque da festa é o almoço de domingo, em que são servidos pratos característicos da culinária alemã-pomerana, como cuca, chucrute, ${ }^{22}$ Eisbein, ${ }^{23}$ linguiça, pato assado, Rievelsback ${ }^{24}$ e sopa de galinha. É ainda oferecida ao visitante a oportunidade de saborear o café colonial, composto de biscoitos, bolos, linguiças, salames, café, chá, suco e o famoso Spickbost, prato que, como registrado na página oficial do evento na internet, ${ }^{25} \mathrm{em}$ 1993 deu origem à mascote da festa:

Meia década após a primeira edição, sentiu-se a necessidade de eleger um mascote para a festa. É no interior de São Lourenço do Sul que se encontra um dos últimos refúgios de uma cultura extinta no local de origem, um prato típico

22 O chucrute, comumente servido com linguiças e carne porco, é um prato elaborado a partir de conserva de repolho fermentado.

23 O principal ingrediente deste prato é joelho de porco, preparado com temperos e acompanhado de chucrute.

24 Interessa comentar que, na edição de 2009 da festa, a comissão organizadora promoveu um concurso culinário de Rievelsback (antes descrito, em nota). À época, cada concorrente teve que preparar cem bolinhos, que foram servidos à comissão organizadora e aos participantes do jantar da Südoktoberfest. Os critérios para avaliação das receitas foram: sabor, higiene no preparo, apresentação, ingredientes da região e receita típica pomerana.

25 Ver: http://sudoktoberfest.com.br/historia-da-sudoktoberfest/. 
da cultura pomerana, o «spickbost», peito de ganso defumado, e foi por isso que o ganso ganhou o título. Posteriormente, em trabalho realizado com os alunos do município, foi escolhido o nome do mascote, que passou a se chamar «Walter».

Em 2012, como resultado de votação popular, foi dado o nome de Wilma para a versão feminina da mascote oficial da festa. O casal de gansos Walter e Wilma personifica, assim, o prato destacado como ícone da identidade pomerana. Podemos identificar no peito de ganso defumado aquilo que Manuel Calvo denominou (1982) prato totem, acionado como marcador de especificidade e diferença. O peito de ganso defumado caracteriza-se, assim, como prato totem, demarcando e exaltando a identidade pomerana para turistas e visitantes da Südoktoberfest.

Contudo, apesar da euforia, na festa, em torno desse prato, o peito de ganso defumado não está presente na dieta contemporânea da maior parte das famílias rurais descendentes de imigrantes pomeranos. Gislaine Maltzahn (2010), que estudou os modos de fazer do peito de ganso defumado na região, mostra em sua etnografia que a criação de gansos é prática mantida por muitas famílias pomeranas, porém o animal é utilizado em outros pratos, tal como ganso assado no forno, enquanto que a elaboração de peito de ganso defumado foi praticamente abandonada ${ }^{26}$.

Apesar de o prato ser apresentado a turistas e visitantes como elemento emblemático da cultura pomerana, são raros os agricultores que, na atualidade, mantêm a produção de peito de ganso defumado. Segundo a senhora Luciane Peske, coordenadora da Südoktoberfest, a pouca oferta do produto chega a se constituir em problema para a organização da festa. Cabe ainda destacar que o peito de ganso comercializado é produto relativamente caro para os padrões locais de consumo, de modo que apenas uma pequena elite local dispõe de meios para adquirir o produto.

Assim é que o consumo de peito de ganso defumado na Südoktoberfest poderia ser interpretado como tradição inventada, entendida, tal como proposto por Eric Hobsbawm (1997), enquanto processo criativo e legítimo. Ao estudar a construção das tradições no contexto de surgimento de estados nacionais, esse historiador argumenta

26 Vale mencionar que a Scharfsauer, sopa que fora muito consumida entre os pomeranos de gerações anteriores, preparada à base de sangue e miúdos de ganso e misturada com farinha de trigo, vinagre e pêssego, parece também estar desaparecendo, pois atualmente poucas pessoas sabem elaborar a receita. 
que tradições são comumente inventadas pelas elites, muitas vezes sem guardar correspondência com a vida cotidiana das pessoas. Desse modo, certos objetos e elementos culturais podem ser apropriados, institucionalizados e ritualizados como meio de reivindicar um passado, uma memória e uma identidade a salvaguardar, já que «não é necessário recuperar nem inventar tradições quando os velhos usos ainda se conservam» (Hobsbawm, 1997: 16).

A Südoktoberfest é uma festa realizada em ambiente urbano e, apesar de inspirada em costumes e alimentação camponeses, o público que se faz presente é composto majoritariamente por turistas e visitantes urbanos. Dessa forma, o que ali se consome não é apenas comida, mas também uma imagem idealizada do rural. Está presente o sentimento de nostalgia e uma retórica de resgate de tradições, que se reflete na iconização de uma receita em processo de desaparecimento. Neste sentido, a escolha do peito de ganso defumado como prato símbolo da festa é construída de fora para dentro do grupo, baseada no discurso de uma «retórica da perda», em que o prato é convertido em objeto de consumo para um público externo, essencialmente composto por citadinos, motivados em consumir o que lhe é apresentado como singular e autêntico. Como veremos na sequência, essa mesma lógica se faz presente na constituição da rota turística rural Caminho Pomerano, em que pratos e receitas tradicionais têm sido agenciados de modo a se tornarem mais atrativos à exploração comercial e desejo de consumo de turistas urbanos.

\section{Caminho Pomerano: O CONSUMO DOS SABORES RURAIS PERDIDOS}

Como pudemos observar quando abordada a constituição da Südoktoberfest, no contexto recente de valorização do patrimônio cultural pomerano, a cultura alimentar do grupo tem sido um dos pilares explorados por atores sociais envolvidos nas políticas locais de patrimonialização. A alimentação ofertada a turistas e visitantes da festa procura não apenas saciar a fome, mas especialmente alimentar o desejo pelo consumo do patrimônio cultural pomerano. É nesse sentido que a alimentação da festa é ideologicamente concebida, de modo a constituir-se também em atrativo turístico.

Sabemos que o ato humano de alimentar-se envolve não apenas a função nutritiva, mas também questões de fundo cultural, na medida em que reflete formas de conceber o mundo (Cantarero: 2002). Comida não é 
somente fonte de energia que permite a continuidade da vida, é categoria cultural nucleante, que pode ser interpretada como linguagem, texto cultural, pois a comida «fala» sobre trabalho, terra, família, relações sociais, informando e formando modos de vida e visões de mundo (Woortmann: 2007; Menasche, Marques \& Zanetti: 2008). A alimentação pode, assim, ser acionada como sinal diacrítico: saberes e práticas da alimentação demarcam pertencimento e diferenciação entre distintos grupos étnicos e é dessa forma que a tradição alimentar chega a ser tomada como manifestação de patrimônio cultural.

Em estudo realizado em um contexto de interação entre turistas e hospedeiros no sul do Brasil, Ana Maria Costa Beber (2012) indica constituirse enquanto campo de atuação do turismo a organização de espaços especializados em que ocorre consumo de patrimônio. Como mostra a autora, os espaços físicos, artefatos, receitas e comidas tradicionais refletem uma dimensão da vida social e seus aspectos simbólicos, ao serem usados como objetos turísticos, convertem-se em bens de consumo estético (Costa Beber: 2012). É nesse quadro que podemos compreender a criação da rota turística rural Caminho Pomerano, espaço em que se realiza a exploração de certos aspectos do patrimônio cultural pomerano, entre eles a alimentação.

Marca o roteiro turístico o fato de muitos dos membros não terem na atividade agropecuária sua principal atividade ou fonte de renda, a participação no roteiro se dando como estratégia de complementação da renda familiar. Assim, vários dos locais de visitação pertencem a famílias que se dedicam ao comércio, atuam no funcionalismo público, trabalham com artesanato, mantendo vínculos efêmeros com atividades associadas ao trabalho na terra, características do modo de vida camponês e pomerano, tema da rota turística.

Cabe ainda ressaltar que o trajeto de aproximadamente 25 quilômetros do roteiro turístico percorre localidades em que predominam famílias de origem alemã - como anteriormente mencionado, originárias da Renânia, não da Pomerânia - que se estabeleceram no meio rural do município de São Lourenço do Sul. Desse modo, o Caminho Pomerano, apesar de ter sua caracterização associada aos pomeranos, é uma iniciativa que não abarca localidades rurais do município em que há concentração de famílias pomeranas. Como já mencionado, a partir do processo de estigmatização dos pomeranos, muitos desses passaram a esconder sua origem étnica, preferindo assumir-se como «alemães». Contudo, se no passado ser pomerano e o que envolvia seu modo de vida era razão de desqualificação, na atualidade nota-se uma inversão dessa classificação. É assim que 


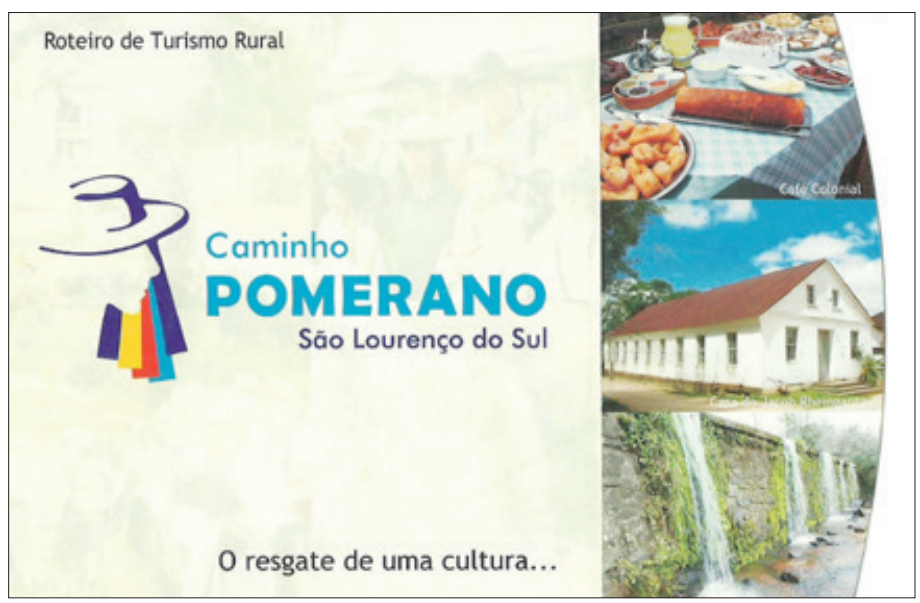

Figura 3: Folder promocional do Caminho Pomerano. Fonte: Associação Caminho Pomerano, 2013.

podemos interpretar a presença de descendentes alemães como integrantes do Caminho Pomerano.

História, turismo e alimentação conformam o tripé a partir do qual foi constituído o roteiro turístico Caminho Pomerano. Nesse sentido, o turista é conduzido a consumir história, paisagens, imagens e sabores de uma tradição rural camponesa, em um ambiente de nostalgia e resgate do passado pomerano (Figura 3). Ao longo do percurso, ao mesmo tempo em que é apresentado um passado idealizado, é dado destaque para a tradição alimentar pomerana, associada a práticas tomadas como genuinamente referidas ao grupo.

Segundo Costa Beber (2012), a valorização do fenômeno culinário a partir de produtos locais ou tradicionais denota conexão com a cultura de um determinado território e permite que esses atrativos turísticos tornemse objeto de consumo, convertidos, muitas vezes, em patrimônio local. $\mathrm{O}$ turismo rural é atividade cultural, econômica e social que oferta para consumidores urbanos atrações de caráter cultural e natural, gerando desse modo condições para sua ativação enquanto patrimônio cultural.

O consumo é um modo de produzir vínculos sociais, na mesma medida em que as mercadorias têm uma vida social (Appadurai: 2008). Assim, a emergência de um objeto no âmbito do consumo o transforma não apenas 
em mercadoria, mas em signo. Como observa Sandra Silva (2012), em estudo que analisa o patrimônio cultural enquanto mercadoria, um bem não representa apenas um objeto qualquer, mas um signo, algo que possui significado cultural e que está inserido em um sistema simbólico. Desta forma, o consumo «ocorre para que o outro que irá receber o objeto possa conhecê-lo melhor, possa ter acesso às suas propriedades físicas, seu sabor, gosto, formas, sonoridade e possa ter um maior conhecimento do que tal objeto representa» (Silva, 2012: 169).

A interface entre consumo, turismo e patrimônio mostra-se presente no contexto da valorização das práticas culturais pomeranas, em que saberes e práticas alimentares do grupo têm sido ativados como patrimônio, ressignificados e apresentados como produto aos turistas. Entre os principais atrativos turísticos do Caminho Pomerano estão a Casa das Cucas e a Casa das Schmiers, pequenos empreendimentos comerciais em que são apresentados modos de preparo de produtos característicos da culinária local. $\mathrm{Na}$ Casa das Cucas, é possível acompanhar o processo de preparo das cucas, degustá-las e adquiri-las. A cuca é prato característico da culinária de origem alemã, presente em muitas regiões de colonização teuta do sul do Brasil. No entanto, chama atenção que, no contexto do Caminho Pomerano, é nomeada Cuca Pomerana, evidenciando apelo a uma suposta autenticidade específica da receita.

Já na Casa das Schmiers, ocorre a degustação e venda de Schmiers, conservas, geleias, doces em calda e frutas cristalizadas, elaborados a partir de produção orgânica de ameixa, beterraba, framboesa, laranja, maça, mirtilo, pera e pêssego. A palavra Schmier deriva do verbo Schmieren, que em alemão significa untar. Schmier é o doce pastoso utilizado entre os agricultores do Sul do Brasil para untar o pão. A Schmier é elaborada a partir de frutas, que são descascadas, picadas ou trituradas e posteriormente cozidas com água e açúcar, diferenciando-se da geleia por apresentar consistência mais pastosa.

Já no ponto final do trajeto percorrido no Caminho Pomerano, no restaurante Frischtick Haus $^{27}$, os visitantes têm duas opções de refeição: o café colonial ou o almoço pomerano. No café colonial, são oferecidos bolos, cucas, doces caseiros, geleias, linguiças, pães, Schmiers, café, leite, sucos, entre uma variedade de alimentos. Caso o turista deseje almoçar

27 Frischtick é um lanche servido geralmente entre o café da manhã e o almoço. Frischtick Haus pode ser traduzido como a «Casa do Frischtick» ou « Casa do Lanche». 
no local, há outro cardápio disponível. Dona Inêz, a proprietária do estabelecimento, explica o que o Frischtick Haus oferece no almoço pomerano:

Bom, o almoço tem os Fleischcuca, que é as tortas de carne, carne de porco. Aí tu decide se quer carne de rês ou carne de frango, uma das duas, mas carne de porco sempre tem. Aí tem o Rievelsback, que é o bolo de batata feito na banha, a salada, o feijão, a maionese pomerana, que é um segredo típico nosso, que a gente explica só na hora. As maioneses naturais que nossas avós faziam, verde, vermelha, amarela.

Também em outros pontos de visitação há degustação e venda de produtos, mas, ao saborear esses pratos tradicionais, no Caminho Pomerano o turista consome adicionalmente a imagem de um rural idealizado. Estudando o caso português, Artur Cristóvão (2002) chama atenção para o fato de existir, entre os citadinos, uma representação do campo como espaço símbolo de liberdade, paisagem, beleza, saúde, argumentando que o valor simbólico do campo e da natureza emergiu como reflexo do desenfreado crescimento urbano que caracterizou o século XX. Para auxiliar na compreensão desse processo, vale ter presente o estudo de Renata Menasche (2009), que propõe observar, a partir das práticas da alimentação, percepções sobre campo e cidade entre agricultores e moradores urbanos. Inspirando-se no trabalho de Eizner (1995 apud Menasche, 2009 : 207), referente ao caso francês, a autora afirma ser identificável «no apelo que, a partir da memória, remete à comida de outros tempos e lugares, uma busca pelo consumo de imagens e sabores perdidos». Assim é que, nesse processo, ao observar a ruralidade afirmada como atributo positivo, do alimento desejado, a autora evidencia que o movimento de revalorização de produtos locais e receitas tradicionais reflete também a busca de um rural idealizado.

As ideias construídas sobre campo, natureza e culturas tradicionais refletem uma revalorização social do rural e do local e induzem à procura pelo que é considerado singular, específico e autêntico (Cristóvão: 2002). De acordo com Contreras (2005: 138), foi justamente a progressiva homogeneização e globalização das práticas alimentares que provocou «certa nostalgia relativa aos modos de se alimentar, aos pratos que desapareceram, suscitando o interesse pelo regresso às fontes dos patrimônios culturais.»

É desta forma que os alimentos ofertados no Caminho Pomerano são acionados como elementos que procuram evocar uma herança cultural associada ao modo de vida rural que, sob a ótica do público urbano 
consumidor destes bens culturais, representaria uma vida mais simples, original, longe do intenso ritmo urbano. É neste quadro que os saberes e práticas da alimentação pomerana têm sido agenciados pelo mercado como forma de promover uma forma de turismo cultural que se desenrola em um ambiente de nostalgia e busca do consumo de imagens e sabores perdidos.

\section{USOS E ABUSOS NA EXPLORAÇÃO DO PATRIMÔNIO CULTURAL POMERANO}

Iniciativas como a Südoktoberfest e a rota turística Caminho Pomerano revelam que história, turismo e alimentação constituem eixos principais a partir dos quais são, no caso em estudo, engendrados os processos de valorização do patrimônio cultural pomerano. A alimentação, em especial, é acionada de forma ideológica, inspirando sentimentos, imaginários e discursos que afirmam a autenticidade e originalidade em torno de características culturais do grupo (Krone \& Menasche : 2016).

Aos olhos do visitante externo, tudo ocorre como se conhecimentos, práticas, receitas tradicionais, comidas típicas e manifestações culturais pomeranas tivessem se mantido imunes à vida contemporânea. As tradições e identidade pomerana são apresentadas como elementos invariáveis. Não obstante, a vida nas comunidades rurais pomeranas se desenvolve de modo bastante distinto daquele apresentado ao público que visita as atrações turísticas.

Um turista desinformado que percorresse o roteiro turístico Caminho Pomerano e participasse da Südoktoberfest ficaria surpreso ao conhecer o mundo rural em que, na atualidade, vivem as comunidades pomeranas do município de São Lourenço do sul. Se tivesse a oportunidade de adentrar na vida de alguma dessas comunidades rurais, o visitante rapidamente perceberia que aquela gente é bem mais «moderna» e menos «tradicional» do que lhe fora apresentado.

A título de exemplo, tomemos o caso do peito de ganso defumado, símbolo da Südoktoberfest. O prato é apresentado para os visitantes da festa como importante herança cultural pomerana, representando a identidade e a riqueza cultural do grupo. No entanto, há muito tempo o peito de ganso defumado deixou de estar presente nas mesas da maior parte das famílias rurais pomeranas. Dona Andréia, agricultora de origem pomerana, é enfática ao afirmar que «o peito de ganso defumado, quem 
sabe fazer são só os antigos, porque as pessoas mais jovens já não sabem nem como vão matar um ganso». Segundo os próprios gestores da festa, no município apenas três famílias dão continuidade à tradição de produção do peito de ganso defumado.

Ainda que o peito de ganso já não faça parte da dieta alimentar da maior parte das famílias pomeranas, isso não significa o abandono de uma alimentação pautada em hábitos culturalmente estabelecidos, pois à mesa dessas famílias estão presentes, entre variados produtos tradicionais, elaborados de forma caseira, alimentos como cucas, doces, linguiças, pães, Schmiers. No entanto, ao lado da produção tradicional de alimentos encontra-se também presente à mesa dessas famílias um número crescente de alimentos que têm origem na indústria, como biscoitos, chocolates, macarrão, refrigerantes, etc.

Ao estudar famílias rurais do município de Maquiné, no sul do Brasil, Mariana Ramos (2007) chamou atenção para o que caracterizou como hibridismo alimentar, observável em relação à mesa camponesa, identificando que o cardápio cotidiano das famílias rurais é marcado pela coexistência de alimentos do campo, produzidos pelas próprias famílias, com alimentos vindos da cidade. Em contexto em que há aproximação crescente entre os universos rural e urbano, a alimentação das famílias pomeranas de São Lourenço do Sul parece refletir esse hibridismo, que coloca lado a lado alimentos do campo e da cidade. Dessa forma, vale reproduzir a história contada por dona Jéssica, agricultora pomerana escutada para esta pesquisa:

É como um senhor me contou um dia, tinha uma pessoa que veio visitar o irmão na colônia, sabe o que tinha na mesa? Cacetinho, ${ }^{28}$ mortadela, margarina e só essas coisas! Ele veio para a colônia querer comer, vamos dizer, linguiça boa da colônia, manteiga, pão feito no forno e tudo coisa assim. Mas tudo que tinha ali na mesa era coisa da cidade.

Neste sentido, se um turista desavisado se dirigisse ao interior do município de São Lourenço do Sul na expectativa de consumir «sabores perdidos», seria surpreendido ao deparar-se com uma alimentação marcada pela ausência de alguns produtos apresentados como tradicionais da cultura pomerana e pela presença de outros tantos presentes no cardápio cotidiano de habitantes das cidades.

28 Cacetinho é termo empregado no Estado do Rio Grande do Sul para referir-se ao tipo de pão pequeno (50 gramas) mais amplamente consumido nas cidades brasileiras, produzido em padarias, feito de farinha de trigo, água, sal e fermento. 
Chama ainda atenção a forma diferenciada como são desenvolvidas as festividades promovidas pelas comunidades rurais pomeranas e pelo poder público municipal. Tanto na Südoktoberfest como no Caminho Pomerano, homens e mulheres que tomam parte na organização se apresentam aos turistas vestidos com trajes que remetem à época da colonização, representando os imigrantes. Como já evidenciado, também na alimentação há preocupação com originalidade e autenticidade de ingredientes e alimentos oferecidos aos turistas. Tal situação difere da observada nas comunidades rurais do interior do município, onde são as próprias famílias rurais, a partir de suas instituições religiosas, que organizam as festas locais. Nessas festas, os organizadores não usam quaisquer adereços ou trajes que pretendam tipicidade, tampouco há preocupação em oferecer um cardápio pautado por autenticidade ou tradição.

Nossa análise encontra paralelo no estudo sobre festas camponesas realizado por Patrick Champagne (1977), na década de 1970, no meio rural francês. $\mathrm{O}$ autor analisa uma festa realizada à moda antiga, a festa na aldeia, cujo objetivo envolve a reconstrução de uma tradição local, contudo realizada para um público externo, urbano. Nessa festa não participam boa parte dos moradores locais, especialmente os mais velhos. Por outro lado, a festa antiga, a festa da aldeia, é um evento realizado por e para a comunidade rural, com participação intensa de membros da comunidade. $\mathrm{O}$ autor mostra que a festa à antiga se constitui enquanto espetáculo, com atores e espectadores, resultado de representação urbana do campesinato. Diante disso, nessa festa os camponeses vivem o paradoxo de representarem a si mesmos, a partir de uma visão folclorizada de seu modo de vida, recriando um passado idealizado. Nessa situação, segundo Champagne (1977), os indivíduos são transformados em objetos de museu, atuando como atores, representando um rural e um modo de vida camponês imaginado pelos citadinos, mas que em realidade os camponeses já não vivem.

O trabalho de Champagne pode iluminar o contexto estudado, em São Lourenço do Sul, pois tanto a Südoktoberfest como o Caminho Pomerano são, em alguma medida, encenações da vida camponesa, com atores e espectadores imprimindo uma versão idealizada do mundo rural pomerano. Dessa forma, as políticas locais de valorização de patrimônio cultural, baseadas em discursos de preservação e autenticidade, pautadas em resgate de traços supostamente originais da cultura pomerana, muitas vezes não encontram correspondência na vida cotidiana das comunidades rurais pomeranas. 
Contreras (2005) ressalta os perigos associados à gestão do patrimônio cultural associada a uma lógica essencialmente econômica, mostrando que categorias como «típico», «rural», «tradicional» são construções idealizadas e submetidas à lógica mercantil. Esse autor marca a distinção entre a lógica do uso econômico do patrimônio e da política cultural do Estado. Segundo ele, a política cultural está baseada essencialmente na manutenção ou recuperação de elementos que representam a manifestação da identidade, porém na lógica econômica a tradição e a autenticidade são amplamente manipuladas pelo mercado, pois há a tendência em preocuparse em tornar patrimônio somente o que é passível de ser convertido em mercadoria, devido à dimensão de espetáculo para o turismo. Nesse contexto, como afirma Contreras (2005: 142-143), as manifestações culturais, entre elas receitas e pratos tradicionais, são, muitas vezes, «recuperadas não tanto pelos indivíduos pertencentes a uma dada sociedade ou cultura particular, mas por outros agentes muito diferentes, associações, corporações, administrações públicas, empresários turísticos etc».

É nesse quadro que entendemos situar-se as iniciativas aqui estudadas, tanto a Südoktoberfest como o Caminho Pomerano, que têm sido explorados e apropriados por atores sociais que, em vários casos, possuem vínculos efêmeros com os modos de vida camponês e/ou pomerano. A Südoktoberfest e o Caminho Pomerano se constituem enquanto espetáculo, sendo em grande medida resultante de representação urbana e exotizada sobre o modo de vida pomerano. Thum (2009) destaca não existir um debate aprofundado sobre a riqueza cultural do grupo, mas a busca do que nela há de exótico, de modo a torná-la atrativa à exploração comercial. É nesse contexto que podemos observar que costumes, receitas e pratos tradicionais pomeranos foram, muitas vezes, recriados, reinventados ou renomeados, de forma a se tornarem mais atrativos à demanda por um consumo nostálgico, de saberes e sabores perdidos.

\section{Considerações Finais}

Ao abordar as políticas de valorização do patrimônio cultural pomerano implementadas nos últimos anos no município de São Lourenço do Sul, foi possível perceber que boa parte das iniciativas locais estão baseadas, principalmente, na tentativa de recuperação de formas tradicionais do «ser pomerano». Nesse processo, o modo de vida pomerano foi constituído enquanto atrativo turístico, em que manifestações culturais, aí inclusos os 
saberes e fazeres da alimentação, foram convertidos em patrimônio cultural, apropriados pelo mercado e ofertados ao consumo.

Nota-se, que a busca por recuperar ou valorizar produtos e comidas tradicionais encontra, em grande medida, paralelo em processos de homogeneização de modos de vida na contemporaneidade. A ruralidade é positivada, sendo o rural apreendido como espaço de contato com a natureza e com culturas tradicionais, ao mesmo tempo em que as ideias construídas em torno desse rural idealizado se expressam na revalorização de pratos e comidas tradicionais, conduzindo ainda à busca pelo que é apresentado como singular, autêntico e exótico. É isso o que pudemos apreender ao analisar a rota turística Caminho Pomerano e a festa típica Südoktoberfest, ou seja, os conhecimentos e práticas da alimentação associados à identidade pomerana foram apropriados pelo mercado como forma de promover uma espécie de turismo cultural pautado pelo clima de nostalgia e de retorno ao consumo de sabores perdidos.

Mas, cabe comentar que, ainda que as políticas locais de valorização do patrimônio cultural pomerano desenvolvidas em São Lourenço do Sul estejam assentadas na recuperação de formas originais e exotizadas do «ser pomerano", isso não significa que essa reconstrução não seja interessante à afirmação da identidade dos pomeranos. As ações públicas municipais levadas a cabo na última década são ainda recentes e novos estudos serão necessários para avaliar se e como tal processo apresenta efeitos para além da mercantilização da cultura pomerana, impactando também na construção e afirmação de uma nova identidade pomerana, superando a condição estigmatizada antes imposta.

\section{REFERÊNCIAS BIBLIOGRÁFICAS}

ABREU, Regina, 2008, «A emergência do 'outro’ no campo do patrimônio cultural.» In: Marília Xavier Cury \& Fabiola Andréa Silva, eds., Museu, identidades e patrimônio cultural. São Paulo, Revista do Museu de Arqueologia e Etnologia, 7: 9-20.

Álvarez, Marcelo \& Luisa PinOtTI, 2000, A la mesa: ritos y retos de la alimentación argentina. Buenos Aires, Grijalbo.

APPADURAI, Arjun, 2008, «Introdução: mercadoria e a política de valor.» In: Arjun Appadurai, ed., A vida social das coisas: as mercadorias sob uma perspectiva cultural. Niterói, Universidade Federal Fluminense.

Calvo, Manuel, 1982, «Migration et alimentation», Information sur les Sciences sociales 21/3: 383-446. 
CANTARero, Luis, 2002, «Preferencias alimentarias y valores de los neorrurales: un estudio en Aineto, Ibort y Artosilla en el Serrablo Oscense.» In: Mabel Gracia, ed., Somos lo que comemos: estudios de alimentación y cultura en España. Barcelona, Ariel.

Champagne, Patrick, 1977, «La fête au village», Actes de la recherche 17 (18): 73-84.

CONTReras, Jesús, 2005, «Patrimônio e globalização: o caso das culturas alimentares.» In: Ana María Canesqui \& Rosa Wanda Díez García, eds., Antropologia e nutrição: um diálogo possível. Rio de Janeiro, Fiocruz.

Costa Beber, Ana María, 2012, Turismo rural, modos de vida em mudança e percepções do rural: um estudo a partir das práticas alimentares de famílias rurais em contexto de interação com turistas. Tese de Doutorado em Desenvolvimento Rural. Porto Alegre: Programa de Pós-Graduação em Desenvolvimento Rural, Universidade Federal do Rio Grande do Sul.

CRISTÓVÃO, Artur, 2002, «Mundo rural: entre as representações (dos urbanos) e os benefícios reais (para os rurais).» In: Mario Rield, Joaquim A. Almeida \& Andyara Lima Barbosa Viana, eds., Turismo rural: tendências e sustentabilidade. Santa Cruz do Sul, Unisc.

Fischler, Claude, 1995, El (b)omnívoro: el gusto, la cocina y el cuerpo. Barcelona, Anagrama.

Gonçalves, J. R. 1996, S. A retórica da perda: os discursos do patrimônio cultural no Brasil. Rio de Janeiro, UFRJ, IPHAN.

HobSBAwm, Eric 1997, «Introdução: A invenção das tradições. » In Eric Hobsbawm \& Terence Ranger, eds., A invenção das tradições. Rio de Janeiro, Paz e Terra.

IEPSEN, Eduardo, 2008, Jacob Rheingantz e a colônia de São Lourenço: da desconstrução de um mito à reconstrução de uma bistória. Dissertação de Mestrado em História. São Leopoldo: Programa de Pós-Graduação em História. Universidade do Vale do Rio dos Sinos.

Krone, Evander E. 2014. Comida, memória e patrimônio cultural: a construção da pomeraneidade no extremo sul do Brasil. Dissertação de Mestrado em Antropologia. Pelotas: Programa de Pós-Graduação em Antropologia, Universidade Federal de Pelotas.

Krone, Evander E. \& Renata Menasche, 2016, «Comida, festa e patrimônio cultural no mundo rural pomerano: a construção da pomeraneidade ao Sul do Brasil.» In: Ellen F. Woortmann \& Julie A. Cavignac, eds., Ensaios sobre a Antropologia da alimentação: saberes, dinâmicas e patrimônios. Natal: EDUFRN.

Maltzahn, Gislaine Maria, 2010, «A transmissão do saber-fazer o peito de ganso defumado entre famílias pomeranas na região sul do Rio Grande do Sul.» In: Anais do II Encontro Internacional de Ciências Sociais: As ciências sociais e os desafios para o século XXI. Pelotas: UFPel. 
Menasche, Renata, 2003, Os grãos da discórdia e o risco à mesa: um estudo antropológico das representações sociais sobre cultivos e alimentos transgênicos no Rio Grande do Sul. Doutorado em Antropologia Social. Porto Alegre: Programa de Pós-Graduação em Antropologia Social, Universidade Federal do Rio Grande do Sul.

MENASCHE, Renata, 2009, «Campo e cidade, comida e imaginário: percepções do rural à mesa», Ruris, 3 (2) : 195-218.

Menasche, Renata, 2013, «Cuando la comida se convierte en patrimonio: puntualizando la discusión.» In: José Luis Mingote Calderón, ed., Patrimonio inmaterial, museos y sociedad: balances y perspectivas de futuro. Madrid: Ministerio de Cultura.

Menasche, Renata, Flávia C. MARQues \& Cândida ZANETTI, 2008, «Autoconsumo e segurança alimentar: a agricultura familiar a partir dos saberes e práticas da alimentação», Revista de Nutrição, 21: 145-158.

MujicA, Marina-Marchi, 2013, Atitude, orientação e identidade linguística dos pomeranos residentes na comunidade de Santa Augusta - São Lourenço do Sul - RS - Brasil. Dissertação de Mestrado em Letras. Pelotas: Programa de PósGraduação em Letras, Universidade Federal de Pelotas.

Poulain, Jean-Pierre, 2004, Sociologias da alimentação: os comedores e o espaço social alimentar. Florianópolis, UFSC.

Ramos, Mariana Oliveira, 2007, A «comida da roça» ontem e boje: um estudo etnográfico dos saberes e práticas alimentares de agricultores de Maquine $(R S)$. Dissertação em Desenvolvimento Rural. Porto Alegre: Programa de Pós-Graduação em Desenvolvimento Rural, Universidade Federal do Rio Grande do Sul.

Roche, Jean, 1969. A colonização alemã e o Rio Grande do Sul. Porto Alegre, Globo.

Salamoni, Giancarla \& Carmen Waskievicz, 2013, «Serra dos Tapes: espaço, sociedade e natureza», Tessituras, 1 (1): 73-100.

SCHneider, Maurício D. \& MenAsche, Renata, 2011, «Pomeranos e plantas medicinais: usos e significados.» In: Anais do XX Congresso de Iniciação Cientifica da Universidade Federal de Pelotas. Pelotas, UFPel. [http://www. igtf.rs.gov.br/wp-content/uploads/2012/10/Pomeranos-e-plantas-medicinais. pdf]

SEYFERTH, Giralda, 1997, «A assimilação dos imigrantes como questão nacional. Rio de Janeiro», Mana, 3 (1): 95-131.

SEYFERTH, Giralda, 2002, «Colonização, imigração e a questão racial no Brasil», Revista USP, 53: 117-149.

Silva, Sandra Sisqueira da, 2012, «Patrimonialização, cultura e desenvolvimento. Um estudo comparativo dos bens patrimoniais: mercadorias ou bens simbólicos?», Revista Museologia e Patrimônio, 5 (1): 157-183. 
SÜDOKTOBERFEST. História da Südoktoberfest. São Lourenço do Sul (RS). [http:// sudoktoberfest.com.br/historia-da-sudoktoberfest/].

Thum, Carmo, 2009, Educação, história e memória: silêncios e reinvenções pomeranas na Serra dos Tapes. Tese de Doutorado em Educação. São Leopoldo (RS): Programa de Pós-Graduação em Educação, Universidade Vale dos Sinos.

Tressmann, Ismael, 2008, «O Pomerano: uma língua baixo-saxônia», Educação, Cultura, Sociedade, 1: 10-21.

Vilela, Charles-Furtado, 2008, «Imigração alemã-pomerana», CIGAInformando. 10 (54): 1.

WAGNER, Alfredo 2010, «Terras tradicionalmente ocupadas: processos de territorialização, movimentos sociais e uso comum.» In: Nelson Delgado, ed., Brasil rural em debate: coletânea de artigos. Brasília, CONDRAF/MDA.

Weiduschadt, Patrícia, 2007, O Sínodo de Missouri e a educação pomerana em Pelotas e São Lourenço do Sul nas primeiras décadas do século XX: identidade e cultura escolar. Dissertação de Mestrado em Educação. Pelotas, Programa de Pós-Graduação em Educação, Universidade Federal de Pelotas.

Williams, Raymond, 1990, O Campo e a cidade, na história e na literatura. São Paulo, Companhia das Letras.

WOORTMANN, Ellen F., 2007, «Padrões tradicionais e modernização: comida e trabalho entre camponeses teuto-brasileiros.» In: Renata Menasche, ed., $A$ agricultura familiar à mesa: saberes e práticas da alimentação no Vale do Taquari. Porto Alegre, UFRGS. 